\title{
Correlation of pressure stimulated currents in rocks with the damage parameter
}

\author{
Cimon Anastasiadis $\left({ }^{1}\right)$, Ilias Stavrakas $\left({ }^{1}\right)$, Dimos Triantis $\left({ }^{1}\right)$ and Filippos Vallianatos $\left({ }^{2}\right)$ \\ $\left.{ }^{1}{ }^{(}\right)$Department of Electronic Engineering, Technological Educational Institution (TEI) of Athens, Greece \\ $\left.{ }^{(}\right)$Department of Natural Resources \& Environment, Technological Educational Institute of Crete, Chania, Greece
}

\begin{abstract}
Pressure Stimulated Current (PSC) experiments were conducted on marble samples to correlate PSC with the damage parameter, $D$. The phenomena and procedures taking place in the vicinity of the fracture limit were observed and analytically described. PSC recordings were conducted by application of uniaxial compressional stress, both at a constant stress rate and at a constant deformation rate. A linear relationship was shown to exist between the emitted PSC and the damage parameter which quantifies the deviation from linear elasticity and the concentration of microcracks.
\end{abstract}

Key words Pressure Stimulated Current (PSC) damage parameter - fracture

\section{Introduction}

Phenomena associated with fracture, particularly those concerning materials of inhomogeneous structure, such as geomaterials, in combination with occurring transient electric phenomena, have always attracted the interest of the scientific community (Hayakawa and Fujinawa, 1994; Hayakawa, 1999). Although there exist important similarities between the fracture of a pristine rock and an earthquake rupture, there are also important differences (Turcotte et al., 2003). Therefore, such phenomena are promising candidates of earthquake precursors (Molchanov and Hayakawa, 1995; Tzanis and Vallianatos, 2002). While deformed, geomaterial generates electrical signals that are assumed to be caused by crack generation and propagation in the

Mailing address: Dr. Cimon Anastasiadis, Department of Electronic Engineering, Technological Educational Institution (TEI) of Athens, Ag. Spiridons Street, GR12210 Egaleo-Athens, Greece; e-mail: cimon@ee.teiath.gr
Earth's crust (Molchanov and Hayakawa, 1998; Vallia-natos and Tzanis, 1998).

In order to understand the mechanisms that produce these electric signals, a number of laboratory experiments of mechanical distress to fracture have been conducted on minerals and rocks (dry and saturated) (Nitsan, 1997; Ogawa and Miura, 1985; Enomoto and Hashimoto, 1990; Hadjicontis and Mavromatou, 1994; O'Keefe and Thiel, 1995; Takeuchi and Nagahama, 2001). These experiments have been combined with numerous studies and recordings of acoustic emissions (Tonolini et al., 1987) due to mechanical stress cause microcracking in rocks as well as the Kaiser effect which takes place in rocks and materials subjected to cyclic loading/unloading (Kaiser, 1953; Beattie, 1983; Lavrov, 2003).

It is known that when mechanical stress is applied upon a rock sample it reacts by emitting electric current (Hadjicontis and Mavromatou, 1994; O'Keefe and Thiel, 1995; Vallianatos et al., 2004). Recent laboratory experiments conducted on Penteli marble samples have confirmed that the application of a uniaxial stress on geomaterial samples is accompanied by the production of weak electric currents to which the term Pressure Stimulated Currents (PSC) has been attributed (Stavrakas et al., 2003, 2004; Anastasiadis et al., 
2004; Vallianatos et al., 2004). The above experimental procedure is described by the term «PSC technique» and consists of recording the currents emitted by geomaterial samples when subjected to either an abrupt stress variation or an extended constant increase in stress rate up to failure. As the magnitude of stress increase reaches the plastic deformation range of the material, microcracks occur randomly starting at the heterogeneities and spreading within the bulk of the sample (Jaeger and Cook, 1979). In the beginning, the structural imperfections produced are uncorrelated but as the density of microcracks increases they interact and a correlated microcrack net structure starts to appear. The microcracks eventually coalesce leading to the irreversible fracture process.

In the present paper PSC emission is studied in two cases: first, PSC emission when the applied stress $S$ is a linearly increasing function of time $(\mathrm{d} S / \mathrm{d} t=$ constant $)$, and second PSC emission at a constant strain, $\varepsilon$, rate $(\mathrm{d} \varepsilon / \mathrm{d} t=$ constant) up to sample fracture.

The stress, $S$, on the material is given as a function of strain $\varepsilon$. For the linear elasticity range it can be stated that

$$
S=Y_{0} \cdot \varepsilon
$$

where $Y_{0}$ is Young's modulus of the undamaged material which is constant in the elastic range. When the stress takes values that lead into the plastic deformation range, then microcracks occur. For a prescribed stress $S$, the strain $\varepsilon$ is greater than the value given by eq. (1.1). Accordingly (Turcotte et al., 2003)

$$
S=Y_{\text {eff }} \cdot \varepsilon
$$

where $Y_{\text {eff }}$ is the effective Young's modulus and it is no longer considered as constant. In the plastic range Young's modulus becomes progressively smaller while stress increases. A more descriptive approach to the results of this process is to introduce a damage parameter $D$ so that (Lemaitre and Chaboche, 1990; Krajcinovic, 1996)

$$
Y_{\text {eff }}=Y_{0}(1-D) .
$$

The damage parameter, $D$, quantifies the devia- tion from linear elasticity and the concentration of microcracks. In general $0 \leq D \leq 1$. When $D=$ $=0$, linear elasticity is obtained with eq. (1.1) valid, but when $D=1$, failure occurs. The damage parameter, $D$, is a function of the applied stress, $S$, only. However in most cases of interest the development of damage in a material is a transient process, so that we have $D(S)$. Thus in the range where deviations from linear elasticity observed, eq. (1.2) can be written

$$
S=Y_{0}(1-D) \varepsilon \text {. }
$$

\section{Material and experimental technique}

The samples used to perform the experiments were of marble collected from Mt. Penteli located in Attica, Greece (Pentelicon or Dionysos marble). Its chemical composition is 98\% calcite and 2\% quartz and other minerals such as muscovite, sericite and chlorite. Its porosity is low, of the order $0.371 \%$. The geometric characteristics of the samples as well as the loading parameters are summarised below.

All samples were cylindrical measuring $106.4 \mathrm{~mm}$ in height, with a diameter of $51 \mathrm{~mm}$. Those of the samples that were compressed at a constant stress rate suffered a pressure increasing at a rate of $20 \mathrm{kPa} / \mathrm{s}$. Those of the samples that were compressed at a constant strain rate, were contracted in one dimension and suffered shortening at a rate of $0.5 \mu \mathrm{m} / \mathrm{s}$. The fracture limit in the former case was 101 $\mathrm{MPa}$ while it was only $88 \mathrm{MPa}$ in the latter as they were measured on the basis of their stressstrain curves.

Stress-strain curves depict the stress required by a material sample to expand or contract by a specified percentage with respect to its initial dimensions. They depend on various factors such as stress history, humidity, water content and porosity. In order to prevent significant variations in the stress-strain curves of the sample under test, all samples were extracted together from the same rock mass and they were kept under the same conditions of temperature and humidity.

Figure 1 shows a typical stress-strain curve of one of the samples used. The values on the 


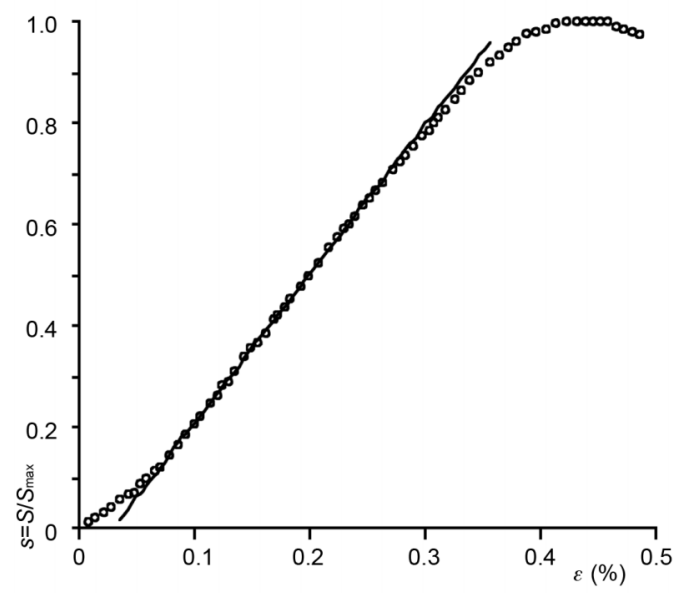

Fig. 1. Typical marble stress-strain curve on normalised stress axis.

stress axis correspond to stress, $s$, normalized by the maximum stress recorded before fracture $\left(S_{\max }\right)$. Each stress-strain, $(s-\varepsilon)$, curve can be divided into three parts: In the first part a non-linear relationship between stress and strain is observed. This is a very short initial quasi-plastic range, that does not extend over 0.1 of $S_{\max }$, which can be attributed to the closing of pores and to probable pre-existing microcracks (Griffith, 1920). The long linear part of the curve corresponds to the elastic range of the material. This range extends up to $s=0.7$, where the plastic behaviour of the sample starts and linearity is no further maintained. This range continues up to fracture. Hereafter, all stress values noted with $s$, will be normalized with respect to $S_{\max }$.

The stress was applied by a loading machine (model MTS-815) capable of applying a maximum force of $\pm 1600 \mathrm{kN}$ and a maximum deformation of $\pm 50 \mathrm{~mm}$. An integrated electronic micro-console (model MTS-453.20), equipped with a load and displacement controller as well as a function generator unit, were used to provide a closed loop control of the servo-hydraulic system. A Keithley electrometer (model 617) was used to measure PSC and all data were stored in a computer hard disk through a GPIB interface. A detailed description of the loading system and measuring system as well as sample mounting and data recording is given elsewhere (Anastasiadis et al., 2004; Stavrakas et al., 2004).

\section{Experimental results and discussion}

During the experiments either the stress rate or the deformation rate were kept constant. As a result, two series of experiments were realized, keeping in each of them either the stress or the strain rate constant.

Figure 2 represents the temporal behaviour of the pressure stimulated current when a marble sample is compressed uniaxially at a constant stress rate of $20 \mathrm{kPa} / \mathrm{s}$ up to the fracture while the inset diagram show the variation of the PSC with respect to the normalized stress. The PSC signal was recorded when the normalised stress exceeded a value of approximately 0.7. At this stress range irreversible structural changes occur due to plastic behaviour of the material. This observation was verified repeatedly (Stavrakas et al., 2004) since at

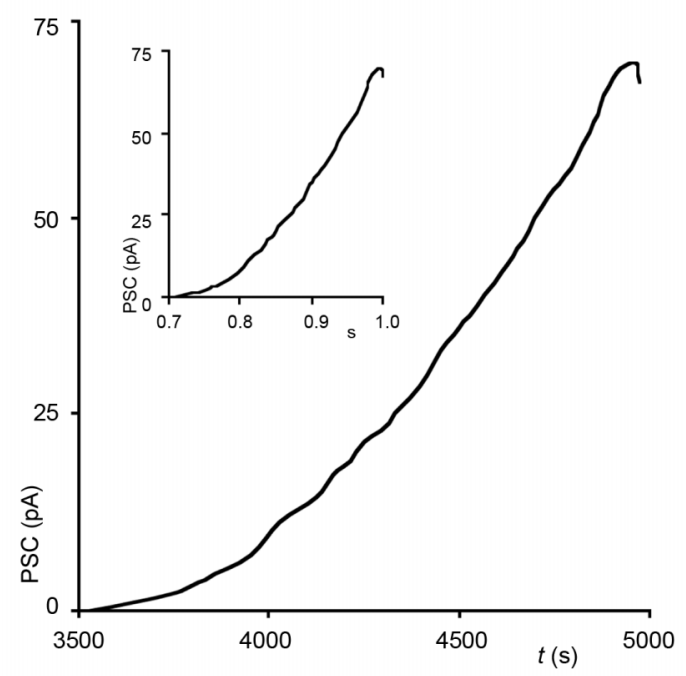

Fig. 2. PSC with respect to time, when stress at a constant rate is applied. The inset diagram shows the PSC versus normalized stress. 
approximately such stress values correspond to the beginning of the plastic range of the material where changes in structure are irreversible due to microcracks taking place (Jaeger and

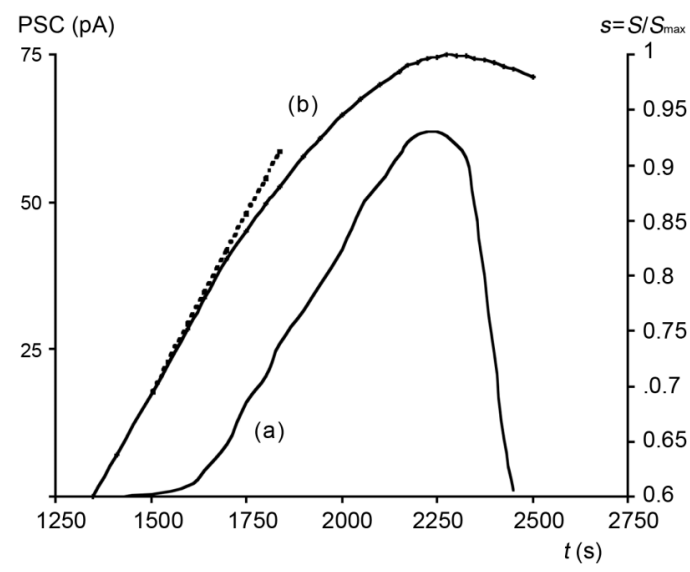

Fig. 3. Detailed representation of the temporal variations of both PSC (curve a) and normalized stress applied on a marble sample (curve b) while the deformation rate is kept constant.
Cook, 1979; Turcotte et al., 2003). In this range $Y_{\text {eff }}$ gets gradually lower than $Y_{0}$. The normalised stress curve at values exceeding 0.7 exhibits a smooth ascending, and it seems to reach a maximum value slightly before fracture. The peak is not clear because the process develops quickly as the stress increase rate is high and the time elapse corresponding to the range $0.9<s<1.0$ is relatively short.

In order to show the peak in detail during the fracture process, uniaxial compression at constant deformation rate was applied. Figure 3 depicts the temporal recording of PSC when the marble sample is subjected to an increase in the uniaxial compression at a constant deformation rate of $0.5 \mu \mathrm{m} / \mathrm{s}$. In the same diagram the temporal variation of the normalized stress $\mathrm{s}$ is represented too. When the material enters the plastic deformation range $(s>0.7)$ the stress rate continuously decreases, and diminishes at $s=1$, when the sample fails. As can be seen in fig. 3 the PSC peak at fracture is clearly distinguished. The emitted PSC acquires a maximum value and consequently decreases; this corresponds to a decrease of the PSC rate which becomes continuously smaller and slightly before
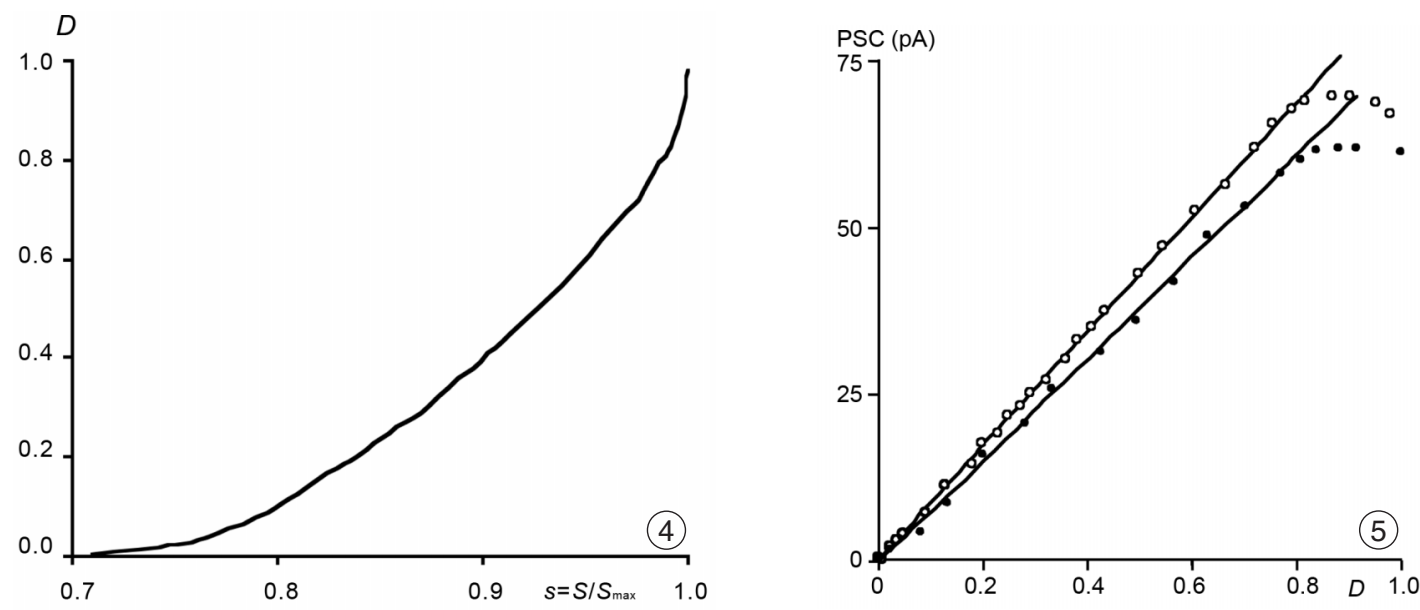

Fig. 4. Variation of the damage parameter, $D$, with respect to the normalized uniaxial stress, $\mathrm{s}$, applied to a typical marble sample.

Fig. 5. PSC with respect to the damage parameter, $D$, when the sample is under constant stress rate conditions: open circles; PSC with respect to the damage parameter, $D$, when the sample is under constant deformation rate: solid circles. 
fracture $(s \approx 0.98)$ the PSC gets to a maximum and an abrupt decrease follows.

Based on the experimental data of the stress-strain curve (fig. 1) the damage parameter, $D$, was determined by the use of eq. (1.4). The diagram of fig. 4 shows the variation of the damage parameter as a function of normalized stress s. It can be seen that the damage parameter, for values of normalized stress greater than 0.7 takes values different from zero and continuously increases.

Figure 5 depicts a correlation between the PSC and the damage parameter, $D$, when the sample is under constant stress rate and constant deformation rate respectively. Both diagrams exhibit a linear relationship between PSC and $D$ in the range of $D<0.8$.

\section{Conclusions}

In this work we correlated the PSC with structural damage introduced in a material by the external application of uniaxial stress. The damage is quantified by the parameter $D$ that can be calculated with good approximation by the use of the stress-strain curve. Correlating the emitted PSC with the damage parameter, $D$, showed a linear relation. This finding holds for $D<0.8$. Since damage mainly occurs at stress levels close to plastic deformation and fracturing, experiments of constant deformation were performed for a better analysis of this process. These experiments validated the linearity between PSC and $D$. From the experiments performed using a constant increase in the strain rate it was verified that PSC reaches its maximum value just before failure at normalized stress of approximately $s=0.98$. Above this level the PSC decreases rapidly.

\section{Acknowledgements}

This work is supported by the project ARCHIMEDES II: «Support of Research Teams of Technological Educational Institute of Athens», sub-project entitled «The electric behavior of geo-materials» in the framework of the Operational Programme for Education and
Initial Vocational Training. It is co-funded $75 \%$ by the EU and $25 \%$ by the Greek Government.

\section{REFERENCES}

Anastasiadis, C., D. Triantis, I. Stavrakas and F. ValLIANATOS (2004): Pressure Stimulated Currents (PSC) in marble samples after the application of various stress modes before fracture, Ann. Geophysics, 47 (1), 21-28.

BeAtTIE, A.G. (1983): Acoustic emission principles and instrumentation, J. Acoust. Emiss., 2, 95-128.

ENOMOTO, J. and H. НАSHIMOTO (1990): Emission of charged particles from indentation fracture of rocks, Nature, 346, 641-643.

GRIFFITH, A.A. (1920): The Phenomenon of rupture and flow in solids, Phil. Trans. R. Soc. London A, 221, 169198.

Hadjicontis, V. and C. Mavromatou (1994): Transient electric signals prior to rock failure under uniaxial compression, Geophys. Res. Lett., 21, 1687-1690.

Hayakawa, M. (Editor) (1999): Atmospheric and Ionospheric Phenomena Associated with Earthquakes (Terra Scientific Publishing Co., Tokyo) pp. 996.

Hayakawa, M. and Y. Fujinawa (Editors) (1994): Electromagnetic Phenomena Related to Earthquake Prediction (Terra Scientific Publishing Co., Tokyo), pp. 677.

JAEGER, J.C. and N.G.W. CoOK (1979): Fundamentals of Rock Mechanics (Chapman and Hall, London), p. 593.

KAISER, J. (1953): Erkenntnisse und Folgerungen aus der Messung von Gerauschen bei Zugbeanspruchung von metallischen Werkstoffen, Archiv Eisenhuttenwesen, 24, 43-45.

Krajcinovic, D. (1996): Damage Mechanics (Elsevier, Amsterdam), pp. 761.

LAVRov, A. (2003): The Kaiser effect in rocks: principles and stress estimation techniques, Int. J Rock Mech. Min. Sci., 40, 151-171.

Lemaitre, J. and J.-L. Chaboche (1990): Mechanics of Solid Materials (Cambridge University Press, Cambridge), pp. 581.

Molchanov, O.A. and M. HayaKawa (1995): Generation of ULF electromagnetic emissions by microfracturing, Geophys. Res. Lett., 22, 3091-3094.

Molchanov, O.A. and M. Hayakawa (1998): On the generation mechanism of ULF seismogenic electromagnetic emissions, Phys. Earth Planet. Int., 105, 201-210.

Nitsan, U. (1997): Electromagnetic emission accompanying fracture of quartz-bearing rocks, Geophys. Res. Lett., 4, 333-337.

O'KeEfe, S.G. and D.V. Thiel (1995): A mechanism for the production of electromagnetic radiation during fracture of brittle materials, Phys. Earth Planet. Int., 89, 127135 .

OGawa, T.K. and T. Miura (1985): Electromagnetic radiation from rocks, J. Geophys. Res., 90, 6245-6249.

Stavrakas, I., C. Anastasiadis, D. Triantis and F. ValLIANATOS (2003): Piezo Stimulated currents in marble samples: precursory and concurrent - with - failure signals, Nat. Hazards Earth Sys. Sci., 3, 243-247.

Stavrakas, I., D. Triantis, Z. Agioutantis, S. MaurigianNAKis, V. Saltas and F. Vallianatos (2004): Pressure 
Stimulated Currents in rocks and their correlations with mechanical properties, Nat. Hazards Earth Sys. Sci., 4, 563-567.

TAKeuchi, A. and H. Nagahama (2001): Voltage changes induced by stick-slip of granites, Geophys. Res. Lett., 28, 3365-3367.

Tonolini, F., A. SAla and G. Villa (1987): General review of developments in AE methods, Int. J. Pressure Vessels Piping, 28, 179-201.

Turcotte, D.L., W.I. Newman and R. ShCherbakov (2003): Micro and macroscopic models of rock fracture, Geophys. J. Int., 152, 718-728.

Tzanis, A. and F. VALLIANATOS (2002): A physical model of electrical earthquake precursors due to crack propagation and the motion of charged edge dislocations, in SeismoElectromagnetics: Lithosphere-Atmosphere-Ionosphere Coupling, edited by M. HAYAKAWA and O.A. MolCHANov (Terra Scientific Publishing Co., Tokyo), 117-130.

Vallianatos, F. and A. Tzanis (1998): Electric current generation associated with the deformation rate of a solid: preseismic and coseismic signals, Phys. Chem. Earth, 23, 933-938.

Vallianatos, F., D. Triantis, A. Tzanis, C. Anastasiadis and I. STAVRAKAS (2004): Electric earthquake precursors: from laboratory results to field observations, Phys. Chem. Earth, 29, 339-351. 